\title{
Archiving the Aboriginal Rainbow: Building an Aboriginal LGBTIQ Portal
}

\author{
Andrew Farrell \\ University of Wollongong \\ farrella@uowmail.edu.au
}

\begin{abstract}
Indigenous LGBTIQ people are a marginalised group that do not have the luxury of representation on a broad range of social and cultural issues. The development of various online projects aims to challenge that. This paper is a discussion of the development of a blog project which supports Aboriginal and Torres Strait Islander LGBTIQ peoples through link sharing online on social media. The themes of identity, social media, and Indigenous activism are rehearsed in this paper to demonstrate the potential for emerging projects that challenge oppressive politics
\end{abstract}

Keywords: Blog; Social Media; LGBTIQ; Queer; Indigenous; Activism

\section{Introduction}

Troy Anthony Baylis (2014) argues that since European contact Indigenous Australians have been stripped of their diverse and customary sexual and gendered practices through the imposition of a new social and cultural order or "cultural default". The cultural default identifies the dominance and oppression of Indigenous peoples through two distinct processes. Firstly, Baylis identifies the deliberate destruction of culture where Indigenous people have been actively dispossessed of their lands, people, societies and cultures through violence. Secondly, Eurocentric ideas about gender and sexuality are exported and imposed onto Indigenous peoples. The very fabric of culture is re-characterised by the recasting of Indigenous peoples into new socio-cultural norms predetermined, generated, and controlled by the dominant culture. This discussion is highlighted by historical developments such as the enforcement of religion in Indigenous communities. For example, traditional marriage systems were overhauled by religious doctrine replacing traditional marriage systems such as polygamy with Christian and Catholic monogamy. This introduced and enforced system assumed the holy distinction of man and woman in its monogamous form as a central pillar of civilisation as a kind of social engineering project erasing cultural traditions considered savage. Mononormative and heteronormative restructuring of Indigenous Australians' everyday lives persisted under Eurocentric regimes which continue to dominate and shape our understanding of Indigenous genders and sexualities today.

Recent developments, as explored in this paper, discuss Indigenous voices of dissent that identify and challenge ideas about gender and sexuality beyond the scope of the Western gender binary and its dominant sexual norms. The reclamation and self-determination of Indigenous LGBTIQ (lesbian, gay, bi-sexual, transgender, intersex, and queer) identity is crucial in these conversations as a 'new frontier' of identity politics that revives knowledge about our ancient diversities as well as asserting our identities as self-defined and contemporary. The development of strategies that enable, prioritise and make visible LGBTIQ peoples is discussed in this paper through Indigenous LGBTIQ voices that speak up and become present online. This article will discuss the blog Archiving the Aboriginal Rainbow and how it was developed as a way to promote and increase the representations of Indigenous Australians' who identify as LGBTIQ. Following the theme of 'Indigenous peoples and activism on social media' this paper will demonstrate how blogging is a form of activism for Indigenous LGBTIQ Australians. This paper will first discuss the social phenomena of blogging and its various uses as it pertains to a broader social context. I will then turn my attention to the use of online platforms by both Indigenous and LGBTIQ communities. This will lead to a discussion of digital archives as social spaces where political discussions, arguments, and 
developments are stored in a 'portal' designed to make Indigenous LGBTIQ standpoints accessible in the age of technology.

I identify as Indigenous and Queer. I am a millennial. I am also active on social media and deeply invested in the political advancement of my communities online. Youth culture is fast becoming synonymous with technology as we frequently engage online as both users and producers. Burnwell (2010) argues that the demands of "participatory culture" online blurs the distinction of user and producer. Participatory culture describes how users become active in identifying gaps in online markets and how they fill those gaps with self-produced content. Outside of the digital space, research reveals that there is a severe gap in literature, research, and representation of Indigenous LGBTIQ Australians (Riggs \& Toone 2016). This dearth of research exists online as there are few projects which identify and share content focused on Aboriginal and Torres Strait Islander LGBTIQ peoples. From this emerges an opportunity to innovate online projects that address this issue. Archiving the Aboriginal Rainbow blog is a response to these issues.

\section{Blogging and Social Media}

Archiving the Aboriginal Rainbow project was based on a personal blog about identity, research developments, and various reflections on gender and sexuality. Blogging was first used to disengage with social media as a separate space to reflect and write. Platforms such as Facebook provide a place for constant and ongoing interaction with personal networks of people through daily personal updates called 'statuses', sharing, responding, commenting on a broad range of topics and issues, and interacting with family and friends. Facebook is oversaturated with information and one can get lost in the daily flow. Blogging provides an alternative platform that offers similar functions to Facebook. However, a blog is less about constant interaction as it is centred on producing content. It is a place to write extensively as well as share photographs and embed content. It is a kind of online diary compared to Facebook which centres more on social interaction.

Social media 'pages', or groups, were the first to influence the blog project. Facebook groups such as Black Rainbow - which is a Facebook page dedicated to sharing Indigenous LGBTIQ articles - demonstrates the effectiveness of social media link sharing. The creator of the page, Dameyon Bonson, self-identifies on the Facebook page which has also since grown into a developing social enterprise (http://www.blackrainbow.org.au/). This inspired me, as the creator of Archiving the Aboriginal Rainbow blog, to identify. I used a 'pinned' permanent post to assure the blogs potential audiences that the blog is run by a person who belongs to the Indigenous LGBTIQ community and someone who works and advocates for that community. The blog presents itself as an online portal that shares links to contemporary and historical audio, images, articles, art, and various other items found across the web (Farrell 2014).

As a doctoral student, my work has always been provoked by a growing sense of urgency and responsibility towards the idea that Indigenous LGBTIQ peoples must be heard, present, and accounted for. This call was also a catalyst for my emergent doctoral thesis. The blog project connects to my academic research as it was first used as a repository for information collected for the thesis. The blog is complimentary to my research and utilises the benefits of interaction and sharing online. Independent research can be isolating, (Percy 2014) and sharing materials in the blog is a way to circumvent those feelings. Amassing articles and various online materials for the thesis would eventually be accessible however it was decided that these items should be shared as they are collected. This decision was of personal importance as much as it was a method adopted to assist research.

The project developed further after critical discussions were presented at the Third Asia-Pacific Outgames Human Rights Forum from the 14-16th of May 2013 in Darwin (Equal Opportunity Commission 2014). There, a call to cultivate strategies of LGBTIQ inclusion and visibility for and by Indigenous peoples from transnational, national, and local perspectives across the AsiaPacific region dominated the stage. The theme was "power though action". An inspiring group of Aboriginal transgender women who identified themselves as Sistergirls spoke on their 
experience and asserted that their voices must be heard by the LGBTIQ community here in Australia. From that, an even greater call to action came from Brotherboys (Aboriginal transgendered men) who strongly articulated their need to be known and heard. Their calls for inclusion and solidarity reinvigorated the desire for me to ensure the Archiving the Aboriginal Rainbow advocated alongside LGBTIQ Aboriginal peoples.

Prior to the Outgames Forum was the annual Queer Histories Symposium. One of the sessions held during the symposium was based on how we can "Queer" archival practices: how we can gather, store, promote, historicise, and cement LGBTIQ history as a part of the Australian "story". This session highlighted the ways that LGBTIQ people have developed a material history out of the uncommon objects and rarely heard stories of LGBTIQ peoples. The panel included Kevin Hauniu of Lesbian and Gay Archives of New Zealand, Eric Julian Manalastas LGBT Policy Archives Project (Manalastas), the Centre for Women's Studies, Northern Territory Archives service, and Graham Willett from Australian Lesbian and Gay Archives (ALGA). These various archives, repositories, and research projects reiterated the importance of collecting, identifying, and building narratives from objects and resources.

\section{Archives}

Archiving the Aboriginal Rainbow is informed by Queer archives including three primary institutions and resources: Australia's largest Australian LGBTIQ archive (ALGA), and international projects such as the Arizona Queer Archives (AQA), as well as various archives online including Trove (National Library of Australia). After exploring these various archival collections there was a notable scarcity of content on Indigenous LGBTIQ peoples. This reflects a harsh reality for Indigenous LGBTIQ peoples who have not been and are not currently overly visible in institutions that store our nation's histories. Regardless of modern and progressive expressions to collect LGBTIQ Indigenous materials for storage these archives are often limited to smaller projects as Indigenous LGBTIQ artefacts are not so readily available for collection. Under similar circumstances LGBTIQ collections were lacking in Indigenous archives. These issues are not always the fault of the archive but are a symptom of a broader historical silence. There are various logistical reasons that may shape this current state. This absence may be due to issues such as a lack of research funding. There is no such thing as an endless monetary supply geared towards Indigenous inclusion in archives such as ALGA (Australian Lesbian and Gay Archive) who work on a largely voluntary basis. Limitations are also generated out of the dearth of sources on, by, and from this group which may be collected and preserved. Aboriginal and Torres Strait Islander LGBTIQ histories are not always complimented by literature, nor by the static and ephemeral objects that are catalogued in a traditional archive.

Social media has assisted in alleviating some of the limitations of research in the field of Indigenous LGBTIQ inquiry by making the community accessible. Social networking connects professionals and emerging researchers with networks based on collective interests that otherwise may not have happened offline prior to the proliferation of such sites as MySpace, MSN, Facebook, and Twitter. Archives such as ALGA demonstrate this as they utilise social networks as well as their own online domain to engage a broader audience in order to develop a network of sharing and appreciating intersectional histories. Such archives also create the potential discovery of new items to collect. While archives such as ALGA have a physical institution, it is their use of social media that has mobilised their potential to seek Indigenous materials for archival purposes. ALGA's key principles include:

...to collect and preserve historically significant items that reflect LGBT life in Australia and, secondly, to disseminate this information back into the community through public exhibitions, publications, and programs (Australian Lesbian and Gay Archives).

These principles have informed the Archiving the Aboriginal Rainbow blog project. The blog mobilises ALGA's rationale and deploys their principles to guide further investigation into Australia's LGBTIQ Indigenous history. The archive is a space where Queer subjects put themselves together as historical subjects (Marshal et. al. 2014, p. 2). Archiving the Aboriginal 
Rainbow is aimed at transforming the retrieval and revival of elements of emerging Queer archives to address Indigenous erasure and estrangement by cobbling together historical understandings of sexuality and gender through an appraisal of presences and absences in found materials (Marshal et. al. 2014, p. 2). Archiving the Aboriginal Rainbow "Queers" the archive but it also Indigenises Queer approaches to collecting and presenting items by creating a space that centres on Indigenous LGBTIQ identities.

\section{Social Media Groups}

Progressive online projects undertaken by Aboriginal and Torres Strait Islander LGBTIQ people in social media pages, groups, and community networking are vital to the blog. These include Facebook groups such as Black Rainbow, Sistergirls and Brotherboys Australia, Sisters and Brothers NT "celebrating diversity", Anwernekenhe Us-Mob, Moolagoo Mob, and Black Lemons. These projects are made up of public and private collectives that include allies, families, and extended networks. On these group pages, you can find Aboriginal and Torres Strait Islander LGBTIQ peoples, interact and consult, as well as share in the social atmosphere and access vital information such as emergency services and a place to advertise job prospects for the community. These spaces create and share social events and are often the first to share materials that may be collected by Archiving the Aboriginal Rainbow.

My involvement in these groups has largely remained with gender diverse subcultures of Sistergirls, Brotherboys, transgender, and Queer identified Aboriginal and Torres Strait Islander peoples. The Sistergirl and Brotherboy Facebook group is actively creating history by assisting and fostering a space that is largely made up of a minority who would otherwise be unable to connect and collectivise. This group is vital in mobilising and facilitating discussion and organisation of political calls to action. For example, the group and I have attended events such as Anwernekenhe 2015 conference in Alice Springs as representatives from our collective (Anwernekenhe 6 Organising Committee 2015). We utilised the Facebook group to consult the broader Aboriginal and Torres Strait Islander gender diverse community on issues around HIV awareness which was then presented and discussed at the conference. The community has proven that it is not a page used for likes, popularity, or as a mere display. It is a living hub of activity that aims to benefit the broader community through direct political action.

Over time, this community has become integral to both my personal and professional life. I am now an administrator of that group and use the site to share articles of interest and assist those who need guidance with writing. I am still in search of my identity and place in these networks as a Queer identified person but am able to negotiate and navigate my identity with assistance that is familiar and appropriate to my cultural heritage. The Sistergirl and Brotherboy Facebook group benefits the Archiving the Aboriginal Rainbow blog more directly as it is shared as a pinned post which receives feedback, engagement, support, and criticism from diverse community perspectives.

\section{The Blog}

The collection began with a handful of articles and now stands at approximately two hundred and fifty posts. WordPress.com hosts the project as it provided the best template to share the collection and use it as a repository for research findings that are a result of sifting and trawling the internet for links to share. On this website, the primary function of the blog set out to appropriate my research bibliographies and various found materials that were bookmarked online to form an online portal. Over time the posts have formed an interactive collage of LGBTIQ Aboriginal and Torres Strait Islander Australia that is constantly evolving.

The theoretical distinction of the term 'archive' is important for situating the blog. Theimer (2012) claims that modern digital collections both misrepresent and depart from the traditional use of the term. She uses the term 'digital humanist' to describe those who appropriate the term 'archive' in the digital space. Theimer emphasise the correct usage of 'digital collection' rather than 'archive' to characterise the grouping of materials purposefully selected to be studied and made accessible. Instead of broadening the term Theimer argues 
that the maintenance of the definition should remain centred on the profession. However, the reality is that the term is now broadly appropriated and accepted to describe the storage of data in a web page. The blog utilises the term "archive" as per its online usage. It is not a traditional archive in the sense that it is a repository. Rather, it is an innovative use of some of an archive's traditional ideological frameworks and collecting methods that are appropriated to generate a space specifically designed to foreground representations of Aboriginal and Torres Strait Islander LGBTIQ peoples.

Attributing value to the knowledge production of this collection is also what this project envisions by using the term. By using the term "archive" the blog signals the importance of LGBTIQ Indigenous Australians contribution to social and cultural issues such as marriage equality, incarceration, homelessness, suicide, mental health, and so on. It is of the utmost importance that opinions and contributions to the site are expressed, valued and shared to maintain an equitable distribution of the ideas and realities articulated. This approach distinguishes the blog as it departs from the purpose of the traditional archive which retracts items from view for the purpose of preservation.

Rather than serving as just a repository of information this project is proactively collecting and asserting a range of politics where most archives would be depoliticised or, at least, claim to be. This project ties into the survival of the discourse surrounding Indigenous LGBTIQ issues and may also reinforce the survival of the community itself. When Aboriginal and Torres Strait Islander LGBTIQ people access online resources, it is important that they see representations of people like themselves. When they go online, this project lets them know that they are seen and heard and that they are present and welcome. That kind of rationale would not come about without the blogs continued response to community or its emphasis and interaction with culturally sensitive gendered and sexual identity politics.

\subsection{The "Digital Midden"}

In the broader Aboriginal and Torres Strait Islander communities, Indigenous blogs such as Deadly Bloggers are important for shaping Archiving the Aboriginal Rainbow. Deadly Bloggers, created by Leesa Watego, is the first and only directory of Aboriginal and Torres Strait Islander bloggers (http://deadlybloggers.com/). Watego presented at the Reterritorialising Social Media: Indigenous People Rise Up symposium held at the University of Wollongong on the 26th of November 2015. In a short but illuminating conversation afterwards, Watego responded to how Archiving the Aboriginal Rainbow might be placed amongst other blogging projects by Aboriginal people and how it is situated as a modern cultural practice online.

In her presentation at the Reterritorialising Social Media: Indigenous People Rise Up symposium Watego discussed cultural conceptualisations of blogging online. She demonstrated how blog projects are significant in developing and maintaining cultural specificity. Watego interpreted blogging as an example of a midden (Watego 2015). Middens are fossilised deposits of food waste that tell a story of how food cultures have developed throughout history. Middens are familiar to me as my people were sea foragers who created middens out of seashells and seafood waste. This waste collected over millennia formed layers of history that, when unearthed, functions to inform and re-inscribe elements of past cultural practices into contemporary discourse. Watego used the midden to describe how blogs are one of the many ways that we practice culture today. She describes blogs as middens that collect ideas which ultimately shape our understanding of modern Indigenous cultures. Similarly, Carlson (2013, p. 145) argues a position on cultural continuity where Aboriginal and Torres Strait Islander peoples' interaction online often mirror or adhere to offline expectations and regulations that change over time. Both Carlson (2013) and Watego (2015) argue that the new forms of cultural practice we develop online have a correlation to the culturally distinct realities that we experience and practice outside of the web. In other words, our realities shape the digital footprint accumulated virtually as a midden would physically.

The Archiving the Aboriginal Rainbow blog functions as a contemporary midden of ideas generated by the LGBTIQ Indigenous community online as active, and ongoing. In a more 
personal conversation Watego interpreted the Archiving the Aboriginal Rainbow blog as a curation - an organisation of materials that conveys a central idea or "story". The broader narrative of the blog is situated in the diverse histories, experience, and futures of Indigenous LGBTIQ peoples with no discernible beginning or ending. It is a digital collection anchored in Indigenous ways of sharing, preserving, and handing down stories as our cultures have done for tens of thousands of years. What is collected and shared facilitates stories shared from multiple cultural standpoints influencing how the broader audience may understand Indigenous LGBTIQ identity and diverse perspectives on a broad range of themes including community and individual achievement.

\subsection{The Black Rainbow}

In 2015 Dameyon Bonson, the creator of Black Rainbow, was the first Aboriginal LGBTIQ person to be nominated for a Human Rights Award for his contribution to advocacy and support for Aboriginal and Torres Strait Islander LGBTIQ peoples (Alexander 2015) and in 2016 he won the Dr Yunupingu Award for Human Rights (Hocking 2016). Bonson's achievements through his advocacy online has since led to the development of the Black Rainbow Living Well Foundation for Aboriginal \& Torres Strait Islander LGBTIQ Suicide Prevention (Bonson 2013) as well as Bonson's report Voices from the Black Rainbow (Bonson 2017). Other milestones include the televised news special Brotherboys on Living Black on NITV (NITV 2015) which developed out of the activism of the Sistergirl and Brotherboys Facebook group. The blog also collects and displays the performances and careers of prominent Aboriginal drag queens such as Destiny Haz Arrived, who is a drag celebrity who has appeared at a range of community sporting and social events (Ward \& Costello 2013, p. 18), and is an advocate for HIV awareness and prevention who was a headline act and poster-girl for Sydney's Lesbian and Gay Mardi Gras in 2015 (Mears 2015). As material is generated around these important political, social, and cultural developments it is shared with pride by the Archiving the Aboriginal Rainbow blog.

\section{Posting}

Gathering and depositing into the "digital midden" is a simple process as follows:

1. Search for article and materials to post.

2. Copy and paste the title of the material as it is found. Use original title as the title of the blog post.

3. Embed link to original source into text "Found here".

4. Invariably include a quote of the material in the post.

5. If audio/visual media is shared, the option to directly embed the materials sometimes exists.

6. Create 'tags'.

7. Publish.

The source is often just a click away and its accessibility depends on its host website. I do not claim ownership of the original content found in the external site. In this approach, the blog aims to reiterate the importance of context as emphasised by Theimer (2012). She states that an archivist's work is concerned with the preservation of context which is an essential aspect of demonstrating authenticity (2012). The blog collects without intent to intervene or misinterpret the source materials original context which is why precautions are taken in becoming too descriptive with the use of 'tags'.

Tagging is an efficient and powerful aspect of the project. Tagging is used to categorically describe the themes present in each article. In Archiving the Aboriginal Rainbow, tags act as a kind of visual cartography of materials available across the blog. Tags also grow larger in font as more articles are contributed to the category. The largest tags are currently "Sistergirls", 
"Brotherboys", "transgender", and "stories". This may be subject to criticism as one tag dominates the space and may reflect an imbalance of representation of the LGBTIQ Aboriginal and Torres Strait Islander community online whereas, for example, in the broader Queer community articles relating to homosexuality may be dominant. Tagging is useful for personal research as it identifies the potential for researching new sources to add to the "digital midden" for a more equitable representation of identities across the Aboriginal and Torres Strait Islander LGBTIQ community. Current materials sought for Archiving the Aboriginal Rainbow include materials relating to Indigenous peoples with intersex variations who are underrepresented in the project.

Some of the 'tags' found in the blog are uniquely Indigenous as they reflect specific cultural ideas. "Stories" is a unique tag based on the commonplace use of the term to describe biographical and experiential stories of Aboriginal and Torres Strait Islander peoples - often referred to as a "yarns" (Geia et. al. 2013). One of the posts, for example, shares an audio project by yarns.org.au with three Aboriginal LGBTIQ stories from rural and remote regions (Australian Federation of AIDS Organisations). Our stories are an important guide to our cultures. Archiving the Aboriginal Rainbow contains personal stories, stories of family, community, land, and so on. Tagging centred on themes of gender and sexuality emphasises that our sexuality and our gendered stories are important to us and are not isolated from our experiences of self, family, community, and cultural identities.

The blog is also multi-platform as it uses a connected Twitter account to disseminate the information as it is created. This was purely to extend the reach of the blog and to obtain followers from other popular domains outside of WordPress and Facebook. The Twitter account has a modest following of 53 followers and the blog on Wordpress.com has 41 followers. While Facebook reigns as the place to widely share a link to Archiving the Aboriginal Rainbow, Twitter is used for audiences who may prefer one social platform to another. The blog is gaining increased international viewership and is often found in the first few pages when searching the combination of terms 'Aboriginal' and 'LGBTIQ'. Search engines like Google and WordPress identify the growing numbers through statistical information gathered by the blog. This includes a map of what country the views are coming from, the number of views that pages have received across a range of time periods, and who has liked, subscribed, and commented on the blog.

Views naturally engender commentary. The blog attracts few comments and they are moderated as they are submitted. Most of these comments ask questions about information not provided by the blog. A recent visitor asked a question in regards to an article shared on the blog. This visitor had taken issue with the art that accompanied an article. I referred them to approach the developers of the original source that shared this art. This is an interesting development that speaks to the perceived relationship of the blog to the links that are shared. The blog maintains its purpose as a project that does not generate its own content. Rather, it is an information harvesting platform otherwise known as a "portal". Almasy (2005, p. 621) describes online portal's as a "subject gateway" for specific research based resources in the form of a directory of online resources that arrange content by subject, contains current news stories based on the chosen field, and facilitates research. Archiving the Aboriginal Rainbow blog is situated within this online genre. Interaction in the form of comments on the blog reaches just beyond the parameters of a traditional portal to enable limited but potentially important opportunities of user and developer interaction.

\section{Limitations, Identity, and Authenticity}

Materials sought for Archiving the Aboriginal Rainbow blog are strictly about availability and accessibility online. There are materials beyond this scope that have the potential to be included in the project. However, from the outset, there have always been limitations as to the kinds of materials that can be shared. For example, peer-reviewed journal articles are typically only accessible through research institutions and others must be purchased. The blog is purely a mechanism that assists and directs people to where they may access articles, video, audio, 
and so on. For example, the blog shares links to other websites where users can buy texts such as Colouring the Rainbow: Blak Queer and Trans Perspectives (Hodge 2015). The blog encourages its audience to buy materials relating to Indigenous LGBTIQ peoples and, importantly, support LGBTIQ Indigenous authors such as Alison Whittaker's collection of poetry in the award-winning Lemons in the Chicken Wire (2016).

Historical materials are a challenge for the project. As noted, Aboriginal and Torres Strait Islander LGBTIQ histories have largely been silenced due to the exclusion in research and mainstream discourse surrounding the existence of homosexuality in Indigenous Australian cultures throughout history. Kleinert (2000) argues that early depictions of Aboriginal sexualities by anthropologists are instrumental in the erasure of Indigenous sexual diversity. Their Eurocentric lens, informed by imported ideas about gendered and sexual morality, has generated a mode of representation that continues to suppress the existence of sexually diverse practices in Indigenous societies. This absence of representational focus is challenged by the rise of Aboriginal and Torres Strait Islander gay and lesbian voices which have seized upon opportunities now available to them to articulate their own lives and stories through a wide range of media (Kleinert 2000, p. 295). Today, transgender voices from within the Indigenous LGBTIQ community are pushing those boundaries further. Recent texts argue for the visibility and inclusion of transgender people in Aboriginal and Torres Strait Islander communities by asserting that Indigenous transgender identity pre-dates colonisation (Canny \& McCrumb 2010). This claim is reinforced through various contemporary texts and modern oral histories that follow a similar trajectory experienced by the gay and lesbian community against claims about Aboriginal and Torres Strait Islander peoples that silence our diverse past, present, and futures.

This is a unique example of the ways that Indigenous peoples reclaim their identity. Interrogating and resisting silences about Indigenous genders and sexualities revives important conversations pertaining to Indigenous identity in Australia that extend beyond the LGBTIQ community. Archiving the Aboriginal Rainbow blog is an agent of change in those arenas. The call to recognition promoted though link-sharing facilitates Indigenous LGBTIQ politics to benefit the wider Indigenous community as it reconceptualises how Aboriginal and Torres Strait Islander communities know themselves, their histories and identities.

The authenticity of Aboriginal and Torres Strait Islander LGBTIQ identities is persistently challenged by those who participate in normative ideas about sexuality. The enduring impact of Western cis-gendered and heteronormative domination has re-emerged in instances of lateral violence enacted on social media platforms such as Facebook. The Facebook page for NITV (National Indigenous Television) shared many LGBTIQ articles throughout Mardi Gras season in early March 2017. They shared the article Comment: The Art of Seeing Aboriginal Australia's Queer Potential by artist and scholar Troy-Anthony Baylis (2017). Some responses were accepting and others were not. One person responded:

This is absolute crap. Homosexuality is not part of traditional Aboriginal society or culture. Trying to justify this is outrageous. How dare you try and create such a lie to justify modern day Aboriginal homosexual - Homosexuality is a result of colonisation Never have I herd [sic] men's and women's business be so disrespected by crazy delusional ideologies (unnamed Facebook user).

This comment demonstrates the kind of violence and denial directed towards Aboriginal and Torres Strait Islander LGBTIQ people. Comments such as these have created a need for online safety for Indigenous LGBTIQ people against those who assert that they do not exist, and when they do, are a perversion of a perceived traditional order that is authentically heterosexual.

\section{Safer Spaces Online}

The idea of safety is important for Archiving the Aboriginal Rainbow. Oppression, discrimination, and various forms of violence are issues that greatly affect Aboriginal and 
Torres Strait Islander LGBTIQ peoples. Violence from within community lines is as prevalent as it occurs between LGBTIQ peoples and wider society. Kelly writes:

Bigotry within the queer community often goes by a different name - lateral violence, or, in other words, fighting against each other.... [which is often] directed at one's peers rather than ones true adversaries (Kelly 2017).

Kelly (2017) identifies the ways in which LGBTIQ community engages in and perpetuates forms of oppression such as misogyny, queerphobia, transphobia, racism, ableism, and so on. Kelly suggests that the very idea of a community itself is challenged by the existence of these 'microaggressions' as they persist across various LGBTIQ sub-groups. For Indigenous LGBTIQ people, racism is an issue within the LGBTIQ community. This is highlighted by the experience of racism on social media dating and "hook-up" apps such as Grindr where Indigenous peoples are confronted by racist taunts (Donelly 2016). The establishment of safer spaces online is a response to racism within the LGBTIQ community and is a necessary challenge for platforms such as Grindr and Facebook which utilise methods of safety such as providing options like blocking and reporting abuse. The term "safer spaces" is used here to acknowledge that there is no true safe space free from tension and all forms of violence (https://radicalassembly.wordpress.com/safer-spaces/). Archiving the Aboriginal Rainbow has not received any abusive comments to date. It is however ready to moderate such events as they occur. As racism and homophobia persist on social media it is an anticipated challenge.

Although Archiving the Aboriginal Rainbow has not been subjected to abuse, it has received criticism for sharing articles. The blog has been criticised for sharing articles under claims that I aim to speak for those whose voices are contained in the articles. Ultimately, such criticism produces effects that are counterintuitive of the projects' aims towards inclusion and visibility though the threat of community conflict. As the creator of the project, I must be accountable and adapt to the challenges that may occur. Self-care, reflection, and formulating new approaches is how I, as producer, respond to community violence. While re-strategising is important sometimes the most effective use of technology is infrequent use. Infrequent use can also be counter-productive to asserting and advocating for LGBTIQ representations online however it is important to accept that reflexivity and listening must play a central role in the continuing development of the blog. This does not suggest acquiescence to all forms of criticism. Rather, if the blog is to maintain its focus on inclusivity and political activism, it is important to continually aim for a balance that will allow for critical interaction while also promoting the political goals of the blog.

\section{Diversity}

Archiving the Aboriginal Rainbow aims to reinforce the possibilities of, and for diversity. However, in some instances there are diversities that cannot be displayed and shared due to cultural sensitivity and protocol. Indigenous Australian cultures are not homogenous and the extent of their diversities is deeply complex. Taboos surrounding gender and sexuality vary across Australia's Aboriginal and Torres Strait Islander cultural landscape and the protocol surrounding them are subject to change over time. I was made aware by private message on Facebook that a blog post on Archiving the Aboriginal Rainbow breached a sensitive protocol. The link shared on the blog contained information about traditional genital sub-incision which, as was informed, is highly sacred and taboo for transgender women who belong to the cultural groups who were named. Sharing this article was a further violation of the protocol so the link was removed from public view. Any further sharing of the article would also be potentially criticised - including referencing it in this paper. Issues such as these are a challenge for a blog about visibility and representations particularly of historical records that confirm diverse practices. While such cultural protocols are important to acknowledge, they do not demonstrably encroach on the blog's objectives; in fact, they contribute to our knowledge of ourselves as vastly diversified cultures. 


\section{An Indigenising Project}

Archiving the Aboriginal Rainbow is an 'Indigenising' project. Indigenising is a process of decolonising through deliberate shaping, subverting, and transforming of colonialist power systems to fund Indigenous ways of knowing and being (Tuhiwai Smith 2012, p. 147). The blog is an Indigenising project as it transforms the digital genre of a blog to support Indigenous ways of knowing and being - sharing the many ways that Aboriginal and Torres Strait Islander identities are expressed. Strategies used to maintain Archiving the Aboriginal Rainbow follows approaches and principles of healing, mobilisation, decolonisation (Tuhiwai Smith 2012, p. 121). These principles are informed by Indigenous theorists, scholars, and leaders as a form of respect and connection to the broader Aboriginal and Torres Strait Islander community and Indigenous communities across the globe. The ideas of these people constitutes an assertion of belonging for many and an acknowledgement that we are not alone in our efforts to reframe debates.

Tuhiwai Smith argues that Indigenous researchers may become complicit with colonial processes that alienate, exclude, or isolate activist aspirations (2012, p. 218). As a blogger, researcher, and community member, it is crucial to maintain a level of awareness about the ideas that place the blog as complicit and/or defiant to entrenched and structural imbalances. As discussed, lateral violence can affect intercommunity relationships that may result in exclusion. This is a sensitive issue for Archiving the Aboriginal Rainbow as it is a project that aspires to combat exclusion. Due to the absence of LGBTIQ sub-groups online it may seem that they are excluded within the blog as they are not present or accounted for. However, this is a mere symptom of the broader absence of these peoples in accessible materials across the internet, regardless of original intentions to utilises ideas of resistance adopted from academic and political work aimed at intervening in the ways institutions conceive of Indigenous genders and sexualities (Driskill 2011). Archiving the Aboriginal Rainbow faces challenges unique to terrains of social media. Research and activist aspirations collide on this platform in ways that facilitate a discourse about why various groups are so underrepresented.

\subsection{Indigenous Standpoint and the Cultural Interface}

To provoke discussions of diversity means to identify and challenge the codifying and unquestioning of introduced and imported systems of social organisation which may have become accepted as a fact of Aboriginal life (Hodge 2015). Indigenous ideas about heterosexuality and the binary of man and woman are ultimately challenged by the material shared by the blog regardless of their unifying or conflicting nature. Identity categories found within Archiving the Aboriginal Rainbow are not vetted for the ways that they adhere to the dominant definition of certain terms. Rather, tags such as "Sistergirl" or "gay" are informed by the material that claim the use of the term. This approach is aligned with the notion of 'standpoint' defined by Nakata (2007, p. 214) as an engagement with the social positions that contribute to the complex positionalities of values and ideas that situate Aboriginal and Torres Strait Islander peoples.

Archiving the Aboriginal Rainbow shares the perspectives of Indigenous LGBTIQ peoples as decolonising agents at the "Cultural Interface" (Nakata 2007). Nakata's Cultural Interface Theory is considered here to describe the ways that Indigenous LGBTIQ ideas filter through complex terrains of knowing and unknowing - influencing how we see and know ourselves and others. I first introduced this discussion in my 2015 paper titled 'Can You See Me? Queer Margins in Aboriginal Communities' to describe Indigenous LGBTIQ agency (Farrell 2015). The Cultural Interface, described by Nakata, is a

multi-layered and multi-dimensional space of dynamic relations constituted by... competing and contesting discourses... [which] inform, constrain or enable what can be seen or not seen, what can be brought to the surface or sutured over, what can be said or not said, heard or not heard, understood or misunderstood, what knowledge can be accepted, rejected, legitimised or marginalised (2007, p. 199). 
Nakata points to the complexity of competing systems that shape the existence of gender and sexual diversity within terrains of knowing and being. Archiving the Aboriginal Rainbow functions at the Cultural Interface. The blog addresses the ways that Aboriginal and Torres Strait Islander LGBTIQ people are excluded, silenced, and erased on a digital platform as a response to issues faced by Indigenous LGBTIQ peoples on and offline. Nakata's work sees the Cultural Interface as a site of productivity, in this instance, a site where negotiation and change are possible, where Aboriginal and Torres Strait Islander peoples are agents of provocation and change though making themselves visible, known, heard, understood, and legitimised.

\section{The Re-Shaping and Re-Imagining of Indigenous Politics}

Archiving the Aboriginal Rainbow is informed by what Tuhiwai Smith (2012) calls the 'Indigenous peoples project'. Tuhiwai-Smith describes the Indigenous peoples' project as a modern call to inclusiveness and diversification of Indigenous politics reminding us that our needs and desires as Indigenous peoples are always already diverse. This is strongly emphasised by the sexual and gender diverse members of our communities whose displays of identity become public calls to inclusion. The blog strengthens the re-conceptualisation of the Indigenous people's project by reinforcing calls for the inclusion of LGBTIQ peoples in the advancement of Indigenous politics in Australia.

The blog is built on the re-shaping and re-imagining of Indigenous politics. Driskill (2010) argues that diverse Indigenous LGBTIQ critiques are a part of the ongoing resistance to colonialism through separate and communal standpoints that imagine and perform survival, resistance, and continuity through the assertion of traditional and contemporary knowledge and oppositional politics. Decolonisation does not have a fixed and finite goal (Driskill 2010, p. 70). Nor does Archiving the Aboriginal Rainbow. While maintaining a political focus, having no fixed political destination or outcome is a strength of the blog as it becomes a space to share a wide range of standpoints that may seem to be self-contradictory, conflating, or fundamentally opposed. In addition, having no articulated telos, the blog is open to possibilities, to change, and to future development that may include data and stories not yet considered. Diversity of ideas and contributions in this context means that contributions to the site inform, shape, and re-shape the terrain of knowledge that ultimately characterise the broader LGBTIQ Indigenous community in Australia. The more contributors who speak enable the enrichment of the site and its potential for future development. While engendering solidarity across the LGBTIQ community is a core objective of Archiving the Aboriginal Rainbow, it is understood that solidarity does not necessarily connote a unanimous voice and that multiple standpoints are a central tenet of the blog's expression of solidarity.

The blog locates shared articles that contain potent and topical discussions about racism, antimarriage equality, homophobia, transphobia, and other social and political views that are important to Aboriginal and Torres Strait Islander LGBTIQ peoples. The blog is not only for Aboriginal and Torres Strait Islander LGBTIQ people. It is also catered for consumption by the broader community. By presenting a collection of LGBTIQ content in a convenient and accessible way, Archiving the Aboriginal Rainbow aims to shift some of the responsibilities and pressures experienced by Indigenous LGBTIQ people who are routinely required to justify themselves. This blog alleviates some of those pressures by directing potential allies to undertake their own online research and to be responsible for their own education and understanding of Indigenous diversity.

\section{Conclusion}

Archiving the Aboriginal Rainbow demonstrates how Indigenous LGBTIQ peoples assert their political standpoints online by vocalising our oppression, resisting denial, calling out and challenging violence, and taking ownership of our diversities. Archiving the Aboriginal Rainbow will continue to develop well into the foreseeable future and adapt, when necessary, to accommodate the needs of the audience and the shifting political, social, and cultural grounds that are constantly in flux. Its continuity depends on my continued passion to 
advocate for these communities, a factor I see as a lifetime goal. The blog is a product of my life circumstances, my identity, and my role in community as a researcher and I am inspired to see it has become a beacon of the community functioning to facilitate Indigenous LGBTIQ representations in social media. To bring about political, social, and cultural change it is important to speak up, persist, and refuse to be invisible. Archiving the Aboriginal Rainbow offers users, contributors, researchers and readers an opportunity to collaborate in a spirit of mutual generosity and with a view to understanding and addressing the historical silences that have oppressed our community for too long.

\section{References}

Alexander, D. (2015) "A First for LGBTI Recognition at National Indigenous Human Rights Awards", Star Observer. Available at, http://www.starobserver.com.au/news/localnews/a-first-for-lgbti-recognition-at-national-indigenous-human-rightsawards/142097 [Accessed 2- Sept 2016].

Almasy, E. (2005) "Tools for Creating Your Own Resource Portal: CWIS and the Scout Portal Toolkit”, Library Trends, 53(4): 620-636.

Anwernekenhe 6 Organising Committee. (2015) Anwernekenhe: Remembering Recognising Responding: 21 YEARS. Available at, http://ana.org.au/wpcontent/uploads/documents/Anwernekenhe_6_Program_DRAFT.pdf [Accessed 5 Jan 2016].

Australian Federation of AIDS Organisations. Available at, http://www.yarns.org.au/ [Accessed 5 Jan 2016].

Australian Lesbian and Gay Archives. Available at, http://alga.org.au/ [Accessed 4 Jan 2016].

Baylis, T. (2014) “The Art of Seeing Aboriginal Australia's Queer Potential”, The Conversation, Available at, http://theconversation.com/the-art-of-seeing-aboriginal-australias-queerpotential-25588 [Accessed 1 March 2017].

Baylis, T. (2017) "Comment: The Art of Seeing Aboriginal Australia's Queer Potential”, $S B S$, Available at, http://www.sbs.com.au/nitv/article/2017/03/01/comment-art-seeingaboriginal-australias-queer-potential [Accessed 20 April 2017].

Bonson, D. (2013) Black Rainbow. Available at, https://www.facebook.com/BlackRainbowAustralia [Accessed 11 Jan 2017].

Bonson, D. (2017) Voices from the Black Rainbow: The inclusion of the Aboriginal and Torres Strait Islander LGBQTI, Sistergirls and Brotherboys in health, wellbeing and suicide prevention strategies. Available at, https://dameyon.com/home/voicesfromtheblackrainbow/ [Accessed 1 May 2017].

Burnwell, C. (2010) "Rewriting the Script: Toward a Politics of Young

People's Digital Media Participation”, Review of Education, Pedagogy, and Cultural Studies, 32(4-5): 382-402.

Canny, A \& McCrumb, D. (2010) Sistergirl. Matchbox Pictures \& Plus Films

Carlson, B. (2013) “The 'New Frontier': Emergent Indigenous Identities and Social Media”, in Harris, M., Nakata, M. \& Carlson, B. (Eds.), The Politics of Identity: Emerging Indigeneity, University of Technology Sydney E-Press, Sydney.

Donelly, B. (2016) "Gay Minorities Speak Out Against Racist Slurs on Grindr", Sydney Morning Herald, Available at, http://www.smh.com.au/national/gay-aboriginal-manpublishes-racist-slurs-on-dating-app-20160418-go8zov.html [Accessed 20 April 2017].

Driskill, Q. (2010) "Doubleweaving Two-Spirit Critiques: Building Alliances between Native and Queer Studies", GLQ: A Journal of Lesbian and Gay Studies, 1(69): 69-92. 
Driskill, Q. (2011) "Queer Indigenous Studies: Critical Interventions in Theory, Politics, and Literature”, University of Arizona Press, Tucson.

Equal Opportunity Commission. (2013) "Power Through Action". Available at, http://www.eoc.sa.gov.au/sites/eoc.sa.gov.au/files/attachments/HRF_FLYER.pdf [Accessed 5 Jan 2016].

Eric Julian Manalastas, "LGBT Resources". Available at, http://pages.upd.edu.ph/ejmanalastas/lgbt-resources-o [Accessed 5 Jan 2017].

Farrell, A. (2014) Archiving the Aboriginal Rainbow. Available at, https://indigblackgold.wordpress.com/ [Accessed 4 Jan 2017].

Farrell, A. (2015) "Can You See Me? Queer Margins in Aboriginal Communities”, Journal of Global Indigeneity, 1(1). Available at, http://ro.uow.edu.au/cgi/viewcontent.cgi?article=1010\&context=jgi [Accessed 15 Jan 2016].

Geia, L. K. Hayes, B. \& Usher, K. (2013) "Yarning/Aboriginal storytelling: Towards an understanding of an Indigenous perspective and its implications for research practice", Contemporary Nurse: A Journal for the Australian Nursing Profession, 46(1): 13-7.

Hocking, R. (2016) "Human rights activists recognised at awards night", SBS. Available at, https://www.sbs.com.au/nitv/article/2016/06/10/human-rights-activists-recognisedawards-night [Accessed 28 Sept 2016].

Hodge, D. (2015) "Colouring the Rainbow: Blak Queer and Trans Perspectives", Wakefield Press, Adelaide. Available at, http://www.wakefieldpress.com.au/product.php?productid $=1267 \quad$ [Accessed 5 Jan 2016].

Kelly, C. (2017) "Fight Amongst Yourselves - Bigotry Within the Queer Community", SBS. Available at, http://www.sbs.com.au/topics/sexuality/agenda/article/2017/03/23/fight-amongstyourselves-bigotry-within-queer-community [Accessed 20 April 2017].

Kleinert, S. \& Neale, M. (2000) "Renegotiating Tradition: Urban Aboriginal Art", The Oxford Companion to Aboriginal Art and Culture. Oxford University Press, Melbourne.

Living Black (2015) "Brotherboys", NITV, Australia. Available at, http://www.sbs.com.au/ondemand/video/451014723969/Living-Black-Brother-Boys [accessed 15 Jan 2016].

Mears, J. (2015) “Drag queen Destiny Haz Arrived to duet with Jessica Mauboy at Mardi Gras”, Sydney Morning Herald. Available at, http://www.smh.com.au/entertainment/music/drag-queen-destiny-haz-arrived-toduet-with-jessica-mauboy-at-mardi-gras-20150211-13atoe.html [Accessed 20 March 2017].

Marshall, D. Murphy, K. P. \& Tortorici, Z. (2014) "Queering Archives: Historical Unravelling's", Radical History Review, 120: 1-11.

Nakata, M. (2007) Disciplining the Savages: Savaging the Discipline, Aboriginal Studies Press, Canberra.

National Library of Australia. Available at, Trove.nla.gov.au [Accessed 5 January 2016].

Percy, A. (2014) "Studying a PhD: Don't Suffer in Silence", The Guardian. Available at, https://www.theguardian.com/higher-educationnetwork/blog/2014/mar/25/studying-phd-dont-suffer-in-silence-seek-support [Accessed 20 March 2017].

Riggs, D. W. \& Toone, K. (2016) "Indigenous Sistergirls' Experiences of Family and Community”, Australian Social Work. doi: 10.1080/0312407X.2016.1165267 
Theimer, K. (2012) “Archives in Context and as Context”, Journal of Digital Humanities, 1(2). Available at, http://journalofdigitalhumanities.org/1-2/archives-in-context-and-ascontext-by-kate-theimer/ [Accessed 20 March 2017].

Tuhiwai Smith, L. (2012) Decolonizing Methodologies: Research and Indigenous Peoples, London, Zed Books.

Ward, J. \& Costello, M. (2013) "Respect and Resilience: Shaping the Response to HIV and STIs among Aboriginal and Torres Strait Island Communities", HIV Australia, 11(3). Available at, https://www.afao.org.au/wp-content/uploads/2017/o2/HIVA-113_Respect-and-Resilience.pdf [Accessed 20 March 2017].

Watego, L. (2015) "Reterritorialising Social Media". Available at, http://www.notquitecooked.com/2015/11/reterritorialising-social-media.html [Accessed 15 Jan 2017]

Copyright: (C) 2017 Farrell. This is an open-access article distributed under the terms of the Creative Commons Attribution-NonCommercial 3.0 Australia License, which permits noncommercial use, distribution, and reproduction in any medium, provided the original author and AJIS are credited.

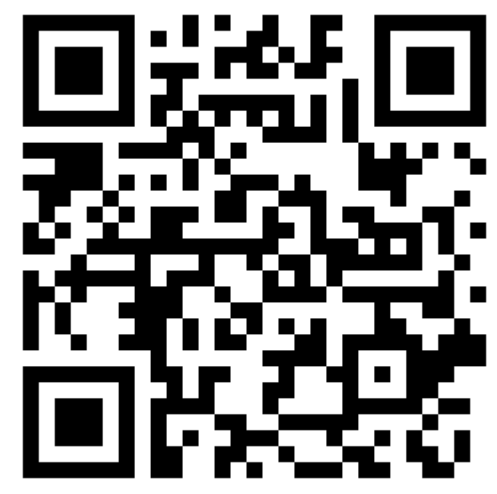

